\title{
The importance of being earliest: birth order and educational outcomes along the socioeconomic ladder in Mexico
}

\author{
Lucio Esposito $^{1}$ (D) Sunil Mitra Kumar ${ }^{2} \cdot$ Adrián Villaseñor $^{3}$
}

Received: 16 October 2018 / Accepted: 5 December 2019 / Published online: 10 January 2020

(C) The Author(s) 2020

\begin{abstract}
We study the effect of birth order on educational outcomes in Mexico using 2 million observations from the 2010 Census. We find that the effect of birth order is negative, and a variety of endogeneity and robustness checks suggest a causal interpretation of this finding. We then examine whether these effects vary across households' economic status, and we find significant heterogeneity across absolute as well as relative standards of living, operationalized as household wealth and relative deprivation. Finally, we find that firstborns' advantage is amplified when they are male, and in particular when other siblings are female.
\end{abstract}

Keywords Birth order $\cdot$ Education $\cdot$ Wealth $\cdot$ Relative deprivation $\cdot$ Gender $\cdot$ Mexico

We are grateful for the suggestions and encouragements of Horacio Almanza, Shaun Hargreaves Heap, Rosanne Tromp, Sarah Tustin, Arjan Verschoor, and seminar audience at the University of Kent. We are also indebted to four anonymous Referees for a wealth of empirical and conceptual suggestions, which have substantially improved the quality of our work. All remaining errors are ours.

Responsible editor: Responsible Editor: Junsen Zhang

Lucio Esposito

lucio.esposito@uea.ac.uk

Sunil Mitra Kumar

sunil.kumar@kcl.ac.uk

Adrián Villaseñor

adrian.villasenor-lopez@york.ac.uk

1 School of International Development, University of East Anglia, Norwich Research Park, Norwich NR4 7TJ, UK

2 King's India Institute and Department of International Development, King's College London, London WC2R 2LS, UK

3 School of Environment and Geography Interdisciplinary Global Development Centre (IGDC), University of York, York, Heslington YO10 5DD, UK 


\section{Introduction}

Since Galton's (1874) study on the preponderance of firstborns amongst eminent persons in society, an array of disciplines have investigated whether there is systematic heterogeneity amongst people depending on their birth order. Recent research on the role of birth order includes the study of intelligence (Rodgers 2014), educational attainment (Monfardini and See 2016), earnings (Bertoni and Brunello 2016), psychological traits (Salmon et al. 2016), malnutrition (Jayachandran and Pande 2017), health outcomes (Black et al. 2016), addictions (Barclay et al. 2016), and consumer behavior (Saad et al. 2005). Such a sustained and multidisciplinary interest in the effects of birth order is perhaps not surprising considering that the alleged source of inequalities between siblings is rooted within the very institution which should protect children from any sort of discrimination: the family.

In this paper, we examine the relationship between birth order and education in Mexico. Our data consist of over 2 million observations from the extended questionnaire of the 2010 Mexican census, a module administered to $10 \%$ of the population that grants statistical representativeness at municipal level. As a first contribution of our paper, we provide evidence of negative birth order effects in Mexico and show that this result is robust to a number of sensitivity analyses and estimation strategies designed to address specific endogeneity concerns. As a second contribution of our paper, we focus on the interplay between households' economic status and birth order. For the first time, the notion of economic status in the study of birth order effects is extended to include not only households' absolute standards of living, but also relative deprivation, i.e., a measure indicating the economic disadvantage relative to other households in the same municipality. We find that both facets of economic status are significant predictors of educational outcomes and that they significantly interact with the birth order variable.

Absolute standards of living affect investments in education via material pathways related to credit constraints, affordability of education, and physical inputs (Basu and Van 1998). By contrast, relative standards of living capture psychosocial pathways whereby relative standing in society affects human capital investments by shaping aspirations and carving social identities (Mayer 2001; Destin and Oyserman 2009 and 2010). It is therefore important to disentangle the potential role of each facet of economic status in shaping the effects of birth order on educational outcomes.

Mexico is an interesting context for studying birth order effects on educational outcomes and for exploring their heterogeneity across economic status. Mexico is an upper middle-income country and OECD member, yet it displays a range of features more typical of low-income countries. Around $46 \%$ of the population lives in absolute poverty according to official national statistics (CONEVAL 2012), and the need to contribute economically to the household is a major determinant of child labor (Alcaraz et al. 2012). Economic inequality is particularly high, placing Mexico at the very top of OECD countries for a range of national and sub-national indicators of inequality (OECD 2016). This significant economic disparity, where substantial parts of the population live in absolute poverty at the bottom while others are considerably welloff at the top, suggests that different dynamics might exist for different parts of the population so far as birth order effects are concerned.

Understanding whether there exist economic gradients in birth order effects is not only interesting in its own right, but can also offer insights into the mechanisms behind 
these effects. While the overall picture of a disadvantage for later-borns we observe for Mexico is consistent with the general evidence for economically developed countries (de Haan et al. 2014), we find that, ceteris paribus, birth order effects are more pronounced at higher absolute as well as relative standards of living. This is in line with evolutionary models of biased parental investment, which postulate that parental attitudes towards risk might strengthen the advantage of earlier-borns in wealthier households (Gibson and Sear 2010; Gibson and Lawson 2011; Hedges et al. 2016). Because higher levels of standards of living imply greater reliability of returns to parental investment and lower vulnerability to risks over which parents have little control (e.g., neighborhood violence), it becomes relatively safer to put "more eggs in one basket," and this benefits earlier-borns over later-borns. At the other end of the spectrum, the evidence that earlier-borns' advantage is smaller in poorer households is also consistent with the existence of child labor. When child labor becomes an option for increasing family earnings, older children are more likely to be sent to work as they are able to command higher wages, and this may erode or even overturn the advantage they may have had towards younger siblings (Emerson and Souza 2008). We also find that while the above patterns are consistent across genders, the advantage of the firstborn is greater when this is a boy, and especially so when all other siblings are female.

The paper develops as follows. In the "Literature review" section, we present a brief discussion of the literature on birth order effects ("A pecking order within the family" section) and discuss how these may be expected to vary at different levels of the two facets of economic status we take into examination ("The interplay between birth order and socioeconomic status" section). The "Data and methods" section describes our data and outlines our empirical approach. The "Results" section presents our findings together with several sensitivity checks. The "Conclusion" section concludes and discusses the implications and limitations of our findings.

\section{Literature review}

\subsection{A pecking order within the family?}

The seminal contribution of Belmont and Marolla (1973) found strong evidence of lower intellectual performance for later-borns. Following this work, an array of models focusing on family interactions and household environment were developed to investigate systematic heterogeneities in intellectual and educational achievements across siblings of different birth orders. These heterogeneities may arise due to the declining intellectual age in the family subsequent to additional siblings (see Zajonc and Markus's 1975 confluence model), resource constraints (see Blake's 1981 resource dilution model), parents' fertility decisions (see the optimal stoppage model by Ejrnaes and Pörtner 2004), and parents' age-related "reproductive quality" (see the biological model of Malaspina et al. 2005). Additional factors studied as possible determinants of birth order effects are parental time allocation (Price 2008; Pavan 2015; Monfardini and See 2016), preferential parenting (Behrman and Taubman 1986; Kessler 1991; Hotz and Pantano 2015; Mechoulan and Wolff 2015; Herd et al. 2016), and personality or behavioral traits (Sulloway 1996; Baer et al. 2005; Black et al. 2017). 
An important source of birth order effects on which the literature has focused is household resources. In line with Becker and Tomes' (1976) idea of a trade-off between quality and quantity of children, Blake's (1981) resource dilution model ascribes earlier-borns' greater intellectual development to the lower number of siblings with whom household resources have to be shared (see also Hanushek 1992). In a similar fashion, de Haan (2010) argues that negative birth order effects may arise due to the financial resource dilution which accompanies the birth of new siblings. Other mechanisms arising from barriers to human capital investments due to resource constraints that have instead been argued to lead to positive birth order effects. Parish and Willis (1993) find that earlier-borns acquire less education and explain this result through credit constraints mechanisms; older siblings would be disadvantaged because they are born when their parents are in the earlier stages of their careers, earn less, and are less able to borrow. An alternative mechanism leading to positive birth order effects is suggested by Emerson and Souza (2008). They explain lower educational outcomes amongst earlier-borns by arguing that when child labor is necessary to boost family incomes, it is the older siblings who go to work because they can command higher wages than their siblings.

As noted by de Haan et al. (2014), the literature seems to suggest a pattern related to the country's level of economic development. Earlier-borns are typically found to have better educational outcomes in high income countries (e.g., Behrman and Taubman 1986; Modin 2002; Black et al. 2005; Kantarevic and Mechoulan 2006; Booth and Kee 2009; de Haan 2010; Härkönen 2014; Barclay 2015; Hotz and Pantano 2015; Mechoulan and Wolff 2015) while later-borns do so in developing countries (e.g., Emerson and Souza 2008; Rammohan and Dancer 2008; Adli et al. 2010; de Haan et al. 2014; Lafortune and Lee 2014; Seid and Gurmu 2015). Interestingly, an analogous within-country socioeconomic gradient is found by de Haan et al. (2014) in Ecuador, and Tenikue and Verheyden (2010) show that earlier-borns have better (worse) educational outcomes in richer (poorer) households in a sample of twelve Sub-Saharan countries. At the same time, there is also evidence deviating from the general pattern related to the country's level of economic development - e.g., Dayioğlu et al. (2009) find negative birth order effects while Turkey and Cho (2011) find positive ones for South Korea.

Evidence from Mexico is scarce and offers conflicting conclusions. Using data from nine schools, Binder (1998) finds an advantage for earlier-borns in terms of years of schooling for girls but not for boys. In contrast, Binder and Woodruff's (2002) study of intergenerational mobility in schooling that tracks families across four cohorts finds some evidence of greater educational achievements for later-borns. In particular, birth order does not influence years of schooling for the first cohort, but increases it in the fourth cohort and with a stronger effect for females. This gender result for the Mexican context is at odds with the findings of Ejrnæs and Pörtner (2004), de Haan et al. 2014, and Härkönen (2014), who instead find weaker birth order effects for females in, respectively, the Philippines, Ecuador, and Germany. Gender could also matter through the likelihood to engage in child labor-e.g., Dammert (2010) finds that in Nicaragua and Guatemala older boys are more likely to engage in paid work. Gutmann (2006) argues that in Mexico parents are often more concerned with the education of the firstborns when they are males, as a result of a macho culture characterized by sonpreference (Filmer et al. 2008) and where having a firstborn male can be seen as a demonstration of manliness (Rojas and Figueroa 2005). 


\subsection{The interplay between birth order and socioeconomic status}

\subsubsection{Absolute standard of living}

The strength of the mechanisms discussed above may differ for households of different socioeconomic status. With regard to the absolute level of standard of living, the main mechanisms discussed in the literature refer to child labor and resource dilution. Livelihood strategies arising in response to economic hardship, such as the involvement of earlier-borns in child labor, can be expected to be more prevalent amongst poorer households. Material resource dilution is also likely to be less of a restraint for richer households, although, if the level of material comfort enjoyed by the household and the economic resources invested in children are commensurate with family earnings and some dilution issues with the arrival of further offspring may in fact arise for most households. ${ }^{1}$ This suggests contrasting influences for these two mechanisms, with child labor (favoring later-borns' schooling) and resource dilution (favoring earlier-borns' schooling) both being more relevant amongst the less wealthy.

Largely neglected in the economics literature, evolutionary models of biased parental investment suggest that wealthier households might invest more in earlier-borns. According to these models, the reason why parents may favor earlier-borns is that these have higher reproductive value (both because older offspring are closer to reproductive maturity and because the rate of juvenile mortality tends to decrease with age) while the reason for favoring later-borns is that the effect of a unit of additional investment on offspring survival is on average higher for younger offspring as they are weaker (Clutton-Brock 1991). These competing drives are typically resolved in favor of earlier-borns, as formalized in the model developed by Jeon (2008). A number of recent contributions argue that this preferential pattern in favor of earlier-borns is stronger in wealthier households (Gibson and Sear 2010; Gibson and Lawson 2011; Hedges et al. 2016). This is because at higher levels of standards of living, there is greater reliability of returns to parental investment and lower vulnerability to the risks over which parents have little control (e.g., susceptibility to disease, neighborhood violence, etc.), so that it becomes relatively safer to put "more eggs in one basket". 2 By contrast for poorer households, higher risks reduce the level of effort per child beyond which success is due to chance (Quinlan 2007). This leads to a less discriminative attitude and to a sort of "bet-hedging" investment strategy in offspring (Liddell et al. 2003).

\subsubsection{Relative standard of living}

Despite the increasing recognition of the role played by relative income in shaping social outcomes (Clark et al. 2008; Clark and D'Ambrosio 2015), to the best of our

\footnotetext{
${ }^{1}$ An interesting perspective on this is offered by the (at first sight counterintuitive) findings of a study based on a sample of 13,176 mothers, where wealthy mothers expressed greater concerns about the economic cost of having large families compared with poorer mothers (Lawson and Mace 2009).

${ }^{2}$ When parents are not averse to inequality in children's outcomes and one child is chosen as the main human capital investment, firstborns would be more likely to be picked for a number of reasons-for example, because they are the closest to being of an economically productive age and they have the highest reproductive potential (being the closest to reproductive maturity).
} 
knowledge the relationship between relative standard of living (independently from its absolute counterpart) and heterogeneity of outcomes across birth orders has been neglected in the literature. To see how birth order may interact with relative deprivation in shaping educational outcomes, it is important to consider that, unlike absolute standards of living (which determine the affordability of education and possibly child labor), a lower position on the economic ladder depresses educational outcomes mainly via aspirations, perceptions, and expectations (Mayer 2001). ${ }^{3}$ This is in line with the theory of identity-based motivation, according to which, since people pursue goals that they believe to be congruent with their socially constructed identities, lower standing in the economic hierarchy leads to underinvestment in education (Destin and Oyserman 2009, 2010). In addition, relative deprivation exerts negative effects on aspects of behavior which affect the ability to sustain investment in human capital formation. These include impulsivity, self-control, susceptibility to boredom, alcohol consumption (Balsa et al. 2014; Mishra and Novakowski 2016), engagement in criminal activities, and passive as well as active bullying at school (Odgers et al. 2015; Napoletano et al. 2016; Vogel and South 2016). For a more in-depth discussion of the link between relative deprivation and educational attainments, see Esposito and Villaseñor (2019).

It is difficult to predict the direction of the interaction between relative deprivation and birth order in shaping educational outcomes. One may expect that relative deprivation is more detrimental for later-borns compared with earlier-borns, because the negative influence of relative deprivation on behavioral aspects may be amplified in later-borns if they are more rebellious and lacking in discipline (see Sulloway 1996). On the other hand, the motivational/aspirational pathway may suggest an equalizing effect of relative deprivation across siblings: if aspirations are suppressed, monetary as well as time investment in education may be reduced to the bare minimum for all siblings, so that educational attainments, and consequently birth order effects, would be "leveled down." In light of the evidence that lower subjective socioeconomic status negatively influences adults' self-assessed intelligence (Kudrna et al. 2010), it is also possible that parents in relatively deprived households invest more in their earlier-borns to try to create more capable carers for younger offspring.

\section{Data and methods}

\subsection{Data and variables}

We use data from the extended-questionnaire section of the 2010 Mexican census. This module is administered to $10 \%$ of the population following a stratified clustered sampling design which covers around 2.9 million households and grants statistical representativeness at municipal level. Since we are comparing birth order outcomes amongst children within the same household, we focus on children aged 6-17 years, and restrict our estimations to households who have at least two siblings. We also exclude the children of mothers whose age at first birth was lower than 13 or greater

\footnotetext{
${ }^{3}$ Quoting Mayer's (2001) influential sociological work, "If children feel relatively deprived, they may be less inclined to study or stay in school. Relative deprivation can also make parents feel stressed and alienated, lowering their expectations for their children or reducing the quality of their parenting" (p. 4).
} 
than 40, since their children might have poorer outcomes on account of physiological factors arising from maternal age. Our final dataset consists of 2026 million observations from 2452 municipalities.

Our outcome variable is on-track grade enrollment-i.e., whether the child is enrolled in the expected grade given her age ( \pm 1 year). This is an important educational indicator because being "off track" (due to late entry and/or grade repetition) has been shown to lead to higher school dropout rates, lower educational attainments, poorer labor outcomes, greater behavioral problems, and negative externalities on other students - with evidence spanning both high- as well as low-income countries (Byrd et al. 1997; Jimerson 1999; Glick and Sahn 2010; Manacorda 2012; García-Pérez et al. 2014; Jaekel et al. 2015). Children in Mexico are expected to start primary school at age six. Primary school consists of six grades, followed by three grades of secondary and three grades of "preparatoria" or high school. Currently, both "basic" schooling (primary + secondary) and high school are mandatory, but enforcement mechanisms are weak. The problem of being "off track" is particularly severe in Mexico, where at the time of our data grade repetition rates at any schooling level were well above the OECD average despite high levels of school enrollment (UNESCO 2007, OECD 2011), and where detrimental effects of grade repetition were found to be important across the educational spectrum including primary school (Gibbs and Heaton 2014).

In our main results, we derive the birth order variable by including any child who has a mother or father residing in the same household and inferring the birth order from their age. Since in a small number of cases there are multiple families within the same household, this approach to assigning birth ranks allows for some children to have the same birth order if they have different parents, and as a robustness check we also estimate birth order effects for such households separately. Robustness checks are carried out with two alternative ways of assigning birth order ranks within the household - which differ with regard to the children included in the ranking, in particular in the case of multiple-family households (more on this below). With regard to the econometric operationalization of the birth order variable, we estimate (i) specifications employing raw birth order variables (i.e., birth order dummies), as well as (ii) specifications using the relative definition of birth order used by Ejrnaes and Pörtner (2004) and Dayioğlu et al. (2009) — viz. $(r-1) /(N-1)$, where $r$ is the raw birth order and $N$ is the total number of children in the household. While this variable is less granular than birth order dummies, it lessens the problem of larger families potentially driving the birth order result due to the positive correlation between raw birth order and household size. Indeed, adopting this relative definition of birth order substantially reduces the correlation between birth order and household size in our data-from 0.50 in the case of birth order dummies to 0.03 in the case of relative birth order.

We conceptualize socioeconomic status in terms of absolute wealth and relative wealth (relative deprivation). Given the lack of income data at household level, we construct an asset index to measure absolute wealth. The extended questionnaire of the Mexican census contains a rich set of variables about the quality of the dwelling, durable goods ownership, and access to basic utilities that allows us to compute a household asset index through principal component analysis (typically found to be a useful indicator for the study of educational outcomes, e.g., Filmer and Pritchett 2001; McKenzie 2005; Mazzonna 2014). Given the discrete nature of the data, we follow polychoric principal component analysis developed by Kolenikov and Angeles (2009). 
The correlation between our municipality mean asset index and the official municipality mean income estimated by CONEVAL (2012) is high ( 0.81 for linear correlation and 0.91 for rank correlation), giving some validation to our wealth measure.

In our main models, relative deprivation is quantified by applying the widely used Yitzhaki (1979) measure to our asset index, which quantifies relative deprivation as the gap between the economic resources of a household and those of richer households in the reference group. The reference group is defined according to a geographic proximity criterion (i.e., people living in the same municipality), in conformity with Deaton's (2001) view that "people almost certainly compare themselves to their immediate geographical neighbors" (p. 21). The linear functional form in the Yitzhaki (1979) index implies that relative deprivation in the comparison with richer individuals is assumed to increase with constant slope. To relax this assumption, we carry out robustness checks with the concave index proposed by Esposito (2010), which accounts for the idea that sensitivity to relative deprivation progressively levels off in the comparison with richer individuals. As an additional robustness check, we also use the (own-generated) mean municipal wealth as well as the (data-provided) mean income in the municipality- these indices based on reference-group means have often been employed in the literature as an alternative metric for relative deprivation (e.g., Ferrer-i-Carbonell 2005; Luttmer 2005).

We control for a rich set of child and household characteristics in order to separate birth order effects from the influence of other correlated characteristics which are also likely to shape educational outcomes. We control for the child's gender and age gap from the previous-born sibling, and dummies for whether the child has a disability, has a blood relationship with the household head, and has both parents living in the household. In particular, the inclusion of age gap from the previous sibling is in order to control for the potential effects of sibling spacing separately from those of birth order. At household-level, we control for the household head's gender and age, average years of education amongst adults, the number of families residing in the household, household size and the number of siblings, whether the household has an indigenous background and is a social program recipient, mother's age at first birth, and the households' economic status in terms of absolute and relative wealth (see below for details). Finally, we control for three municipality characteristics which might influence educational outcomes directly or indirectly: the number of schools per child (as a proxy for supply of education), municipality population (to control for size effects), and an index of migration to the USA (capturing a potentially important form of group-level aspirations which might influence expectations from schooling and the perceived returns to education more broadly). ${ }^{4}$ Descriptive statistics are provided in Table 1. Boys and girls are in almost equal proportions, just over a fifth have an indigenous background and $1.8 \%$ suffer from a disability, and almost three quarters of children are on track.

\subsection{Empirical strategy}

Our aim is to understand the relationship between birth order and on-track grade enrollment - i.e., whether the child is enrolled in the expected grade given her age

\footnotetext{
${ }^{4}$ The migration index is calculated by CONEVAL (Mexican National Population Council) on the basis of information including the percentage of households with members in the USA, with visiting members who live in the USA and with returning members who lived in the USA between 2005 and 2010.
} 
Table 1 Summary statistics

\begin{tabular}{|c|c|c|c|c|}
\hline Child and household characteristics $(N=2026,469)$ & Mean & (S.D.) & Min & $\operatorname{Max}$ \\
\hline \multicolumn{5}{|l|}{ Birth order and on-track enrollment } \\
\hline Relative birth order & 0.471 & 0.399 & 0 & 1 \\
\hline Birth order $($ raw $)=1$ & 0.326 & - & 0 & 1 \\
\hline Birth order $($ raw $)=2$ & 0.334 & - & 0 & 1 \\
\hline Birth order $($ raw $)=3$ & 0.192 & - & 0 & 1 \\
\hline Birth order $($ raw $)=4$ & 0.086 & - & 0 & 1 \\
\hline Birth order $($ raw $)>=5$ & 0.061 & - & 0 & 1 \\
\hline $\begin{array}{l}\text { On-track grade enrollment (child } \\
\text { enrolled in correct grade for age) }\end{array}$ & 0.747 & - & 0 & 1 \\
\hline \multicolumn{5}{|l|}{ Child characteristics } \\
\hline Female & 0.490 & - & 0 & 1 \\
\hline Age (years) & 11.415 & 3.401 & 6 & 17 \\
\hline Age difference from previous-born sibling & 2.362 & 2.635 & 0 & 30 \\
\hline Has disability & 0.018 & - & 0 & 1 \\
\hline Child not related to household head & 0.001 & - & 0 & 1 \\
\hline \multicolumn{5}{|l|}{ Household characteristics } \\
\hline Household asset index & 5.355 & 2.373 & 0 & 11.474 \\
\hline $\begin{array}{l}\text { Mean years of education of adults } \\
\text { in the household }\end{array}$ & 6.659 & 3.692 & 0 & 24 \\
\hline $\begin{array}{l}\text { Yitzhaki index of relative deprivation } \\
\text { at municipality level }\end{array}$ & 0.844 & 0.828 & 0 & 7.482 \\
\hline Esposito index of relative deprivation & 0.216 & 0.197 & 0 & 0.998 \\
\hline Household size & 6.140 & 2.176 & 3 & 38 \\
\hline Number of siblings & 3.653 & 1.637 & 2 & 18 \\
\hline Male household head & 0.868 & - & 0 & 1 \\
\hline Age of household head & 42.480 & 10.476 & 18 & 129 \\
\hline Both parents live in the household & 0.860 & - & 0 & 1 \\
\hline Household is recipient of social program & 0.237 & - & 0 & 1 \\
\hline Number of families in the household & 1.224 & 0.523 & 1 & 8 \\
\hline Speaks indigenous language & 0.218 & - & 0 & 1 \\
\hline Mother's age at first birth (years) & 25.692 & 6.001 & 13 & 40 \\
\hline \multicolumn{5}{|l|}{ Municipality characteristics $(N=2452)$} \\
\hline Population & $45,792.548$ & $132,858.940$ & 93 & $1,815,786$ \\
\hline Migration to the USA (index) & 2.691 & 2.311 & 0.000 & 14.356 \\
\hline Schools per child & 0.009 & 0.006 & 0.001 & 0.059 \\
\hline Municipality-level assets index & 5.388 & 1.546 & 1.689 & 9.259 \\
\hline Average income & 1575.884 & 857.064 & 415 & 8902 \\
\hline
\end{tabular}

Notes: This table provides sample statistics for the variables used in our analysis. Relative birth order is defined as $(r-1) /(N-1)$, where $r$ is the raw birth order and $N$ is the total number of children in the household. We do not report standard deviations for indicator variables. 
( \pm 1 year). The binary character of our dependent variable and the high proportion of positive outcomes suggest that a non-linear modeling approach is best suited (Long 1997; Doi et al. 2013: p. 245). This also lends additional potential benefits in terms of consistency (Horrace and Oaxaca 2006) and less susceptibility to problems when the dependent variable is misclassified-i.e., measured with error (Hausman et al. 1998).

Consequently, we employ logit models with and without fixed effects. The fixedeffects logit (also known as "conditional logit") has the added benefit that it considers only those households that display some within-household variation in outcomes, dropping those households where all or no children are on-track-for which no within-household variation across birth order can be observed. Formally, for the $i^{\text {th }}$ child, the logit model estimates

$$
\operatorname{Prob}\left(\mathrm{y}_{\mathrm{i}}=1 \mid \mathbf{x}_{\mathbf{i}}\right)=\frac{\exp \left(\mathbf{x}_{\mathbf{i}}^{\prime} \boldsymbol{\beta}\right)}{1+\exp \left(\mathbf{x}_{\mathbf{i}}^{\prime} \boldsymbol{\beta}\right)}
$$

where $\mathbf{x}$ is a vector of covariates which includes birth order and $\beta$ is a vector of regression coefficients estimated using maximum likelihood. Throughout, standard errors are clustered at household level to allow for within-household correlation.

The fixed-effects logit models' probabilities are conditional on the proportion of positive outcomes within the household. Formally, if the $\mathrm{i}^{\text {th }}$ household has $\mathrm{N}_{\mathrm{i}}$ children, $\mathrm{k}_{\mathrm{i}}$ of whom are on-track, and the $\mathrm{j}^{\text {th }}$ child's on-track outcome is denoted $\mathrm{y}_{\mathrm{ij}}$, then the vector $\mathbf{y}_{\mathbf{i}}$ of outcomes for the household is $\mathbf{y}_{\mathbf{i}}=\left(\mathrm{y}_{\mathrm{i} 1}, \mathrm{y}_{\mathrm{i} 2}, \ldots \mathrm{y}_{\mathrm{ik}}\right)$ and

$$
\operatorname{Prob}\left(\left(\mathbf{y}_{\mathbf{i}} \mid \sum_{j=1}^{N_{i}} y_{i j}=k_{i}\right)=\frac{\exp \left(\sum_{j=1}^{N_{i}} y_{\mathrm{ij}} \mathbf{x}_{\mathbf{i j}} \boldsymbol{\beta}\right)}{\sum_{d_{i} \in S_{i}} \exp \left(\sum_{j=1}^{N_{i}} y_{\mathrm{ij}} \mathbf{x}_{\mathbf{i j}} \boldsymbol{\beta}\right)}\right.
$$

where the set $\mathrm{S}_{\mathrm{i}}$ contains all possible permutations of outcomes within the household such that the number of positive outcomes remains $\mathrm{k}_{\mathrm{i}}$, and $\mathrm{d}_{\mathrm{ij}}$ can take the value 0 or 1 . As mentioned above, this estimator only exploits information from the households where there are some variations in the outcome variable.

Because birth order regressions focus on within-family variation in outcomes, de Haan et al. (2014) note that this leads to the correlation between the child's age and birth order becoming amplified. We follow the strategy commonly used to address this problem, and include dummies for the child's age in all regressions. Finally, as Kantarevic and Mechoulan (2006) have argued, we would expect birth order effects to function at least in part via the age of the mother and her age at first birth. That is, even though this age might not cause birth order effects, we would expect it to be associated with the factors which would drive this relationship, such as intelligence, physiological condition, own employment, and ambition for children—not all of which are observed or can be controlled for. In light of this crucial relationship, we control for the mother's age at first birth and square thereof. ${ }^{5}$

\footnotetext{
${ }^{5}$ It should be noted that we do not control for the mother's current age; this is because we include mother's age at first birth and dummies for the child's age.
} 


\section{Results}

\subsection{Birth order effects}

Tables 2 and 3 presents estimates for the relationship between birth order and on-track school enrollment, reporting logit and fixed-effects logit estimations, respectively. We report results for the full sample, households that consist of single families, and households with multiple families. In both tables, the key variables of interest are relative birth order (columns 1-3) and birth order dummies (columns 4-6). The models in Table 2 include the full list of covariates, while for those in Table 3, household-level covariates are washed out by the fixed-effects estimation approach.

The birth order variables display negative and highly significant coefficients $(p<0.001)$ across all specifications. This indicates that the probability of being ontrack is lower for later-borns, regardless of which subsample or model is adopted and whether we operationalize birth order through a relative single variable or through birth order dummies. ${ }^{6}$ As mentioned above, whereas logit models involve both within and between-household comparison, fixed-effect logit focuses exclusively on withinhousehold comparisons, showing that the finding of negative birth order effects indeed relates to within-household dynamics. Further, the fixed-effect logit models provide a first general indication that unobservables at household level are unlikely to drive this result since they condition on all factors - observed and unobserved - that determine the within-household proportion of on-track enrollment. ${ }^{7}$ To evaluate the magnitude of birth order effects, we plot Fig. 1a quantifying predicted probabilities from model 4 in Table 3 over the domain of birth order while holding all other covariates at their average values. ${ }^{8,9}$ Fig. 1a confirms that later-born children have lower outcome probabilities, with an average gap in on-track enrollment between first and lastborn of approximately $6 \%$.

In Table 2, our economic status variables have the expected sign (positive for absolute wealth and negative for relative deprivation) and are highly significant in all regressions $(p<0.001)$. The results for absolute wealth and relative deprivation should be seen as disentangling the roles of absolute and relative standards of living rather than simply as providing "mirror-image" pieces of information. This is because, while typically higher wealth corresponds to lower relative deprivation, this correspondence holds strongly only within a reference group - i.e., a household may have both lower absolute wealth and lower relative deprivation than another if they live in a poorer municipality. This can be seen also from correlation statistics. When calculated within individual municipalities, the correlation between absolute wealth and relative

\footnotetext{
${ }^{6}$ In the models with birth-order dummies a test for their joint significance is also highly significant.

${ }^{7}$ Yet it is important to bear in mind that although the conditional logit strategy minimizes potential endogeneity problems arising from the correlation between household size and birth order, the characteristics of children might still endogenously determine subsequent fertility and thus birth order and household size. See Ejrnaes and Pörtner (2004) for a theoretical model with endogenous fertility.

${ }^{8}$ In non-linear models regression, coefficients can be interpreted directly only in terms of their sign but not their magnitude, since the marginal effect of each covariate depends on the levels of all the other covariates.

${ }^{9}$ We present these probabilities in terms of the gap in on-track enrollment (\%) relative to the firstborn's outcome. This seemed the clearest presentational strategy since the fixed effect that determines the household proportion of positive outcomes in a fixed-effects conditional logit model cannot be identified - and therefore absolute predicted probabilities provide little information while differences in predicted probabilities do.
} 


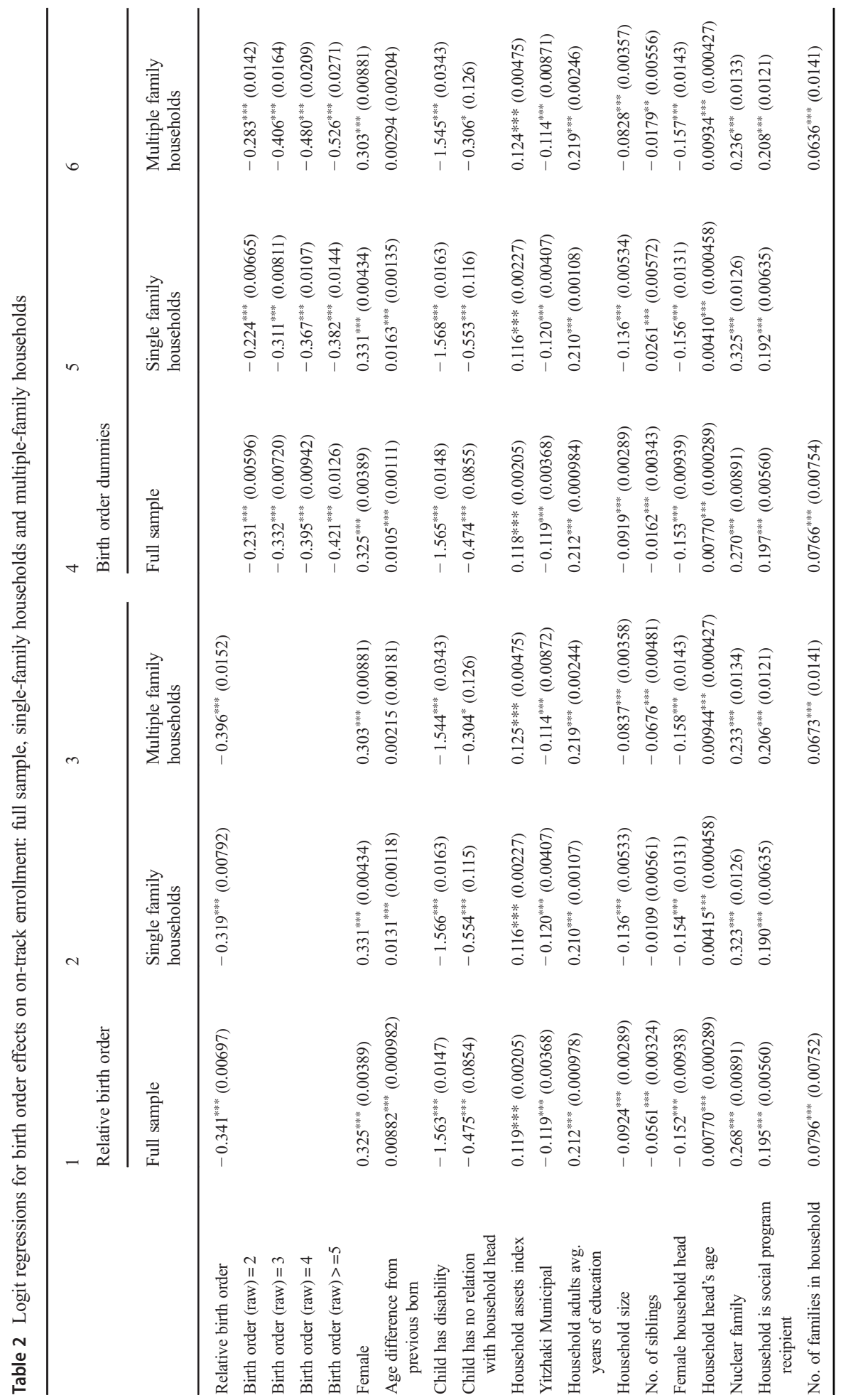




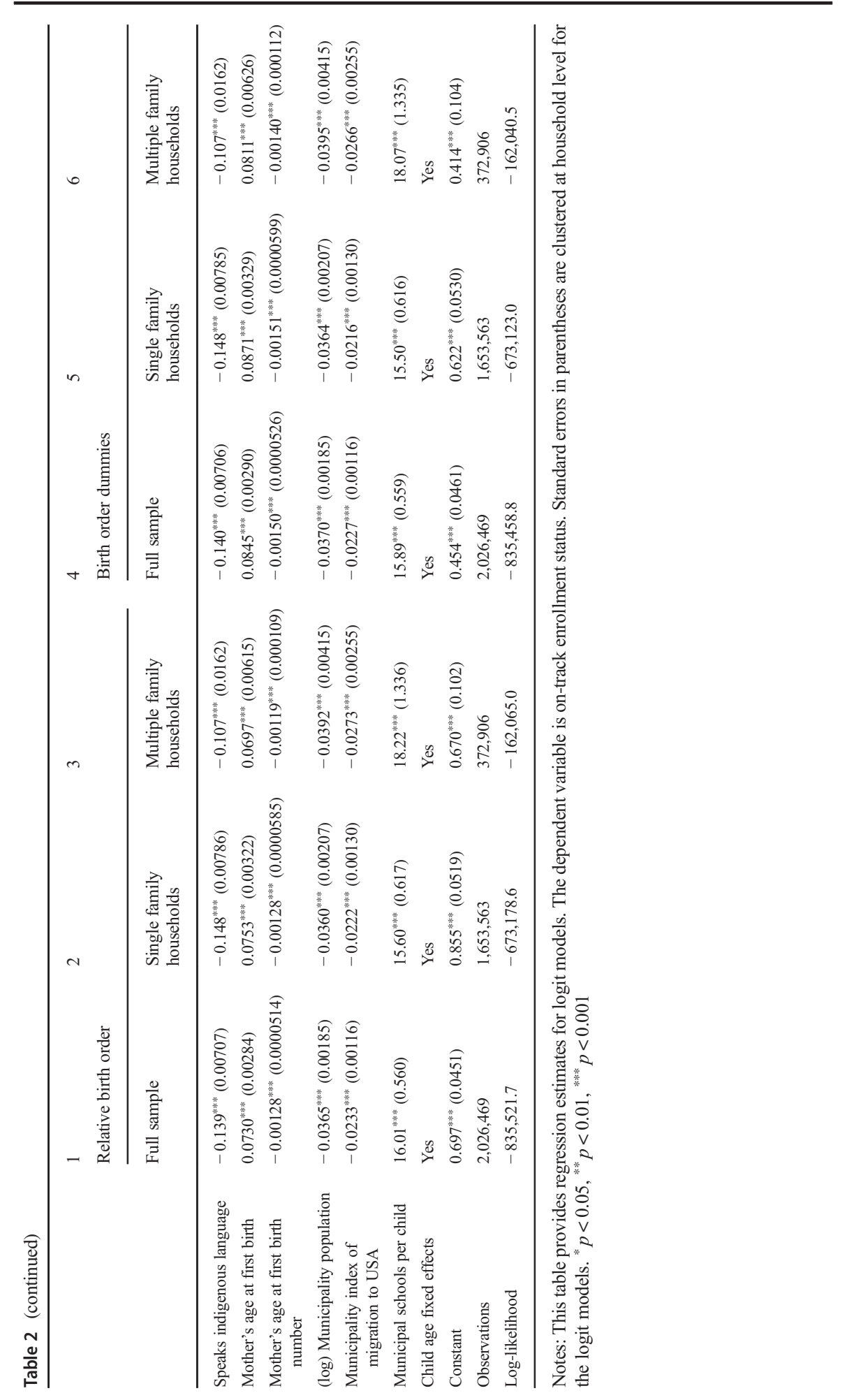


deprivation is very high (ranging between -0.76 and -0.99 ); however, when calculated over our whole sample, correlation is only moderate $(-0.48)$.

Results for our other covariates are also intuitive and in line with the educational literature. Girls are more likely to be in school, in line with the gender reversal of education in Latin America (World Bank 2012). Negative predictors are having a disability, being in a female-headed household (which in Mexico this is often equivalent to being a single-mother family), sibship size (due to increasing competition for resources), household and municipality size, and migration intensity - which is likely to decrease the investment in home education since this is poorly remunerated in the USA (Massey and Espinosa 1997). Being indigenous (proxied by speaking an indigenous language) also has a negative effect and this is in line with the findings of Patrinos and Psacharopoulos (1997). Positive predictors are adult education, being a beneficiary of a social program, being in a nuclear family, age difference from the previous sibling, school availability, and household's head age - in line with Debowicz and Golan (2014). ${ }^{10}$

\subsection{Endogeneity concerns and subsample analyses}

Is the negative association between birth order and on-track enrollment causal? Besides the general indication from the fixed-effects logit estimates that household-level unobservables are unlikely to be driving the results, we estimate a number of models which address different challenges to a causal interpretation. Table 4 addresses the concern for a specific form of endogeneity which could arise due to unobservables (such as fertility decisions) driving both the number of siblings as well as birth order outcomes. Since we would expect that these unobservables remain fixed in subsamples defined by the number of siblings, we run fixed-effects logit specifications 1-3 (relative birth order) and 4-6 (birth order dummies) using subsamples with 2, 3, and 4 siblings, respectively. In all cases, birth order coefficients are negative and highly significant $(p<0.001)$, suggesting that results are unlikely to be driven by unobservables related to sibship size. Here, and in the tables that follow, we display only the main explanatory variables of interest-results for the other covariates mirror those discussed above relative to Tables 2 and 3 and are available upon request. The corresponding predicted probabilities (based on Table 4 models 4-6) are summarized in Fig. 1b, which shows that slopes are negative and that the outcome gap between first and lastborn children rises with the number of siblings.

A different concern arises from potential sample censoring of two kinds. On the one hand, future plans for as yet unborn children might influence the educational outcomes of current children; on the other, older children may have left the household and thus might not be observed, leading to biased estimates of birth order effects. While we cannot address these issues entirely due to the nature of our data, we address these concerns by censoring our sample in two alternative ways. First, by restricting the sample to mothers who are less than 32 years of age at the time of the survey: their children are in general quite young, and thus it is less likely that older siblings have left the household. Second, by restricting the sample to mothers who are over 44 years of

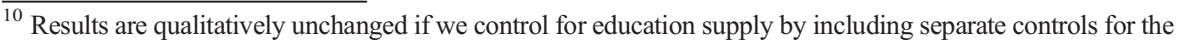
availability of primary and secondary schools.
} 


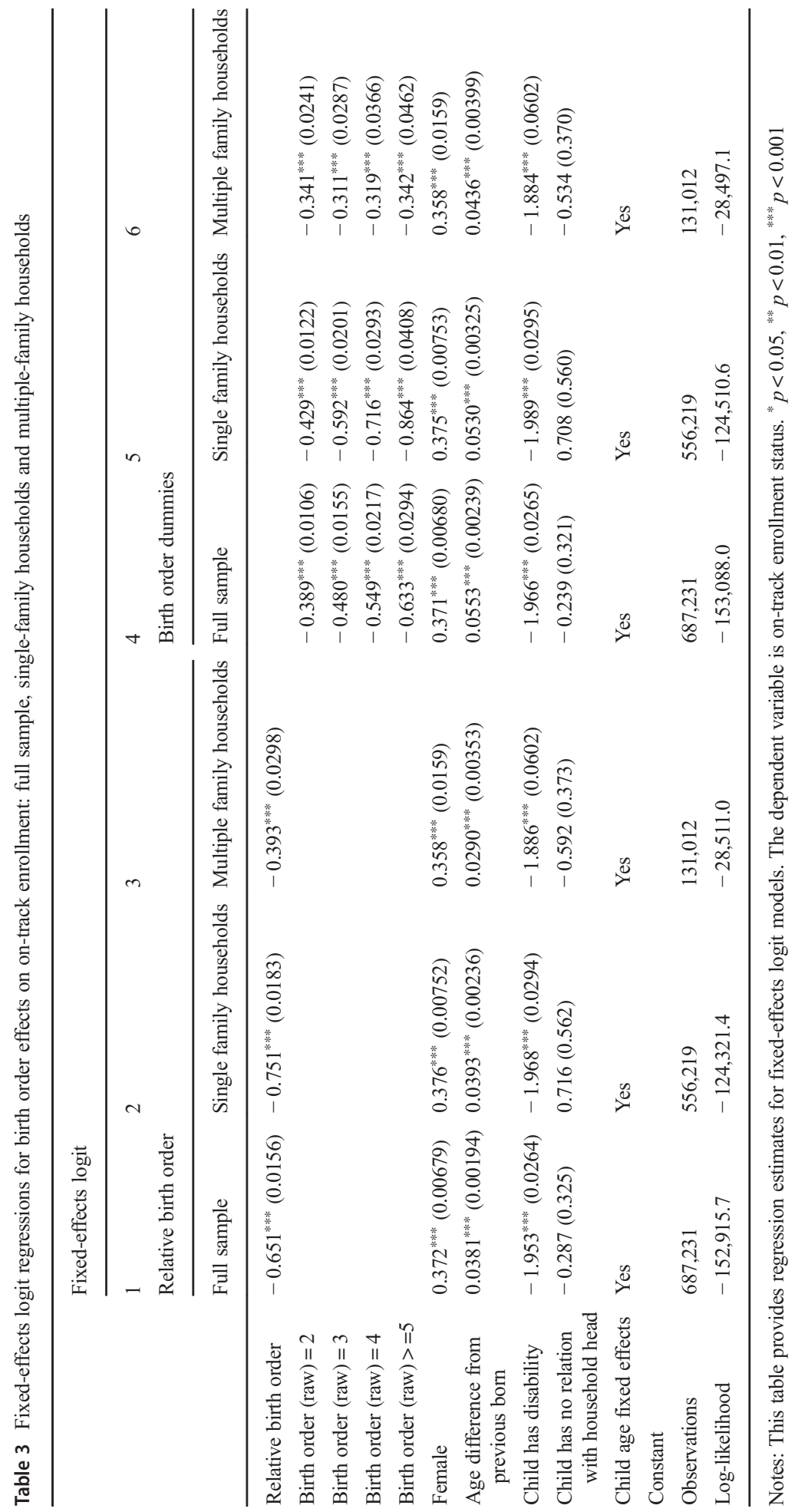




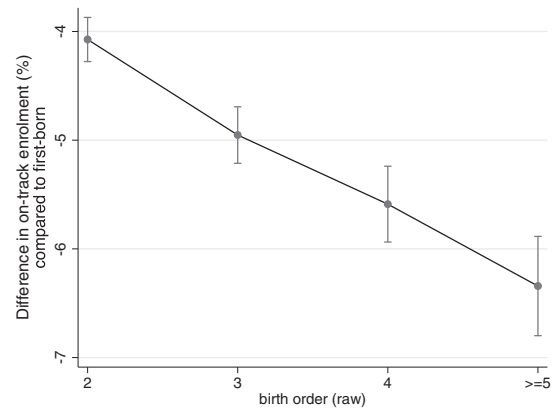

(a) Full sample

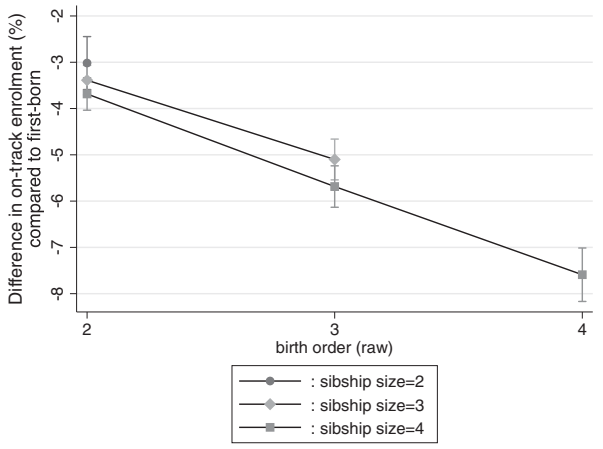

(b) Samples by sibship size

Fig. 1 Relationship between birth order and on-track enrollment. Notes: This figure shows the gap in on-track enrollment $(\%)$ between lastborn and firstborns in terms of sample-average predicted probabilities obtained using model 4 in Table 3 (for part a) and models 4-6 in Table 4 (for part b) at different values of birth order holding all other covariates fixed at their sample values

age at the time of the survey: the rationale for this is that older mothers can be assumed to have completed their fertility (Kantarevic and Mechoulan 2006; Emerson and Souza 2008; Dayioğlu et al. 2009), and thus it is unlikely that there are any as yet unborn siblings, plans for whom might influence the educational outcomes of current children. We provide graphical summary results for regressions based on subsamples identified by these mother's age censoring regressions in Fig. 2, which displays also summary results for fixed-effects logit models estimated on subsamples defined according to an array of socioeconomic and demographic characteristics. For each of these regressions, birth order effects are negative and highly significant $(p<0.001)$-full regression results are provided in Appendix 1. The figure illustrates the difference in the probability of being on-track between the lastborn and the firstborn with $99.9 \%$ confidence intervals.

\subsection{Birth order along the economic ladder}

Our finding of a negative relationship between birth order and educational outcomes echoes the evidence typically emerging for high-income countries (e.g., Black et al. 2005; Conley and Glauber 2006; Kantarevic and Mechoulan 2006; Booth and Kee 2009; de Haan 2010). If we consider that Mexico is an OECD member and is classified as an upper-middle income country, our finding can certainly be seen to fit this picture. At the same time, however, moving away from economic aggregates and looking at how economic resources are distributed, Mexico displays disparities in standards of living as well as levels of absolute poverty which are typical of countries at lower levels of economic development. Around $46 \%$ of the population were living in absolute poverty according to the official national statistics at the time of the census (CONEVAL 2012) and the need to contribute economically to the household is a major determinant of child labor (Alcaraz et al. 2012). Economic inequality is particularly high, placing Mexico at the very top of OECD countries in a range of inequality indicators at national and sub-national levels (OECD 2016). The extent of 


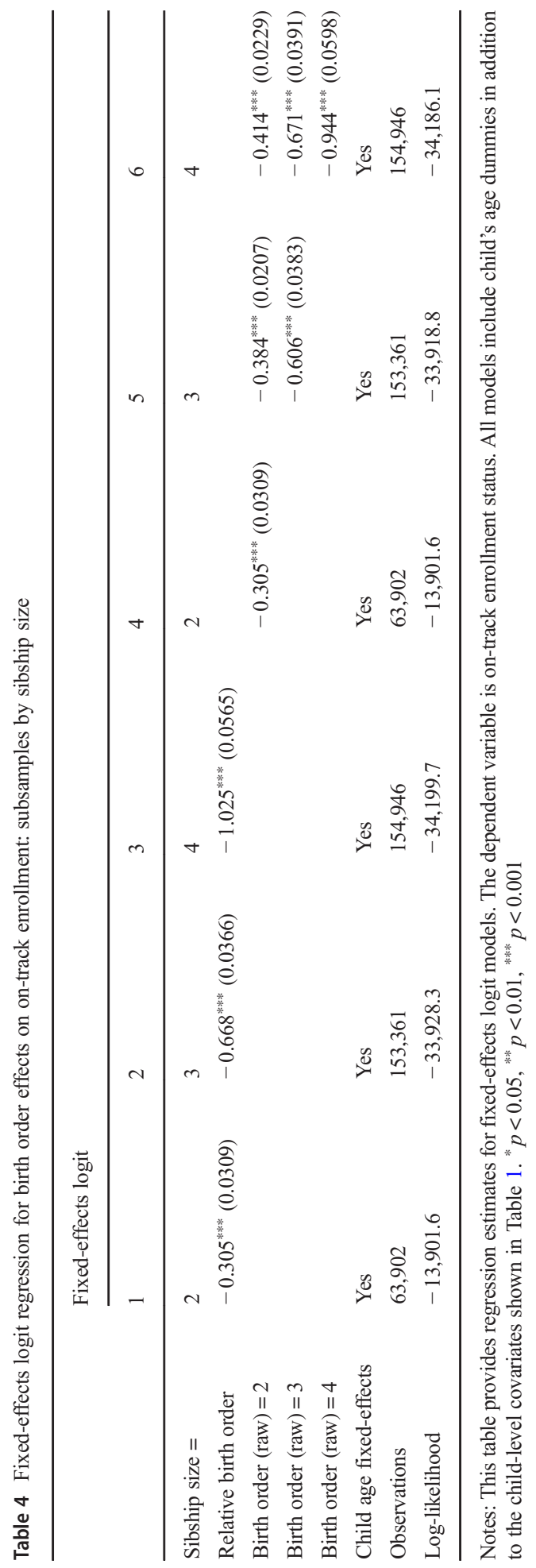




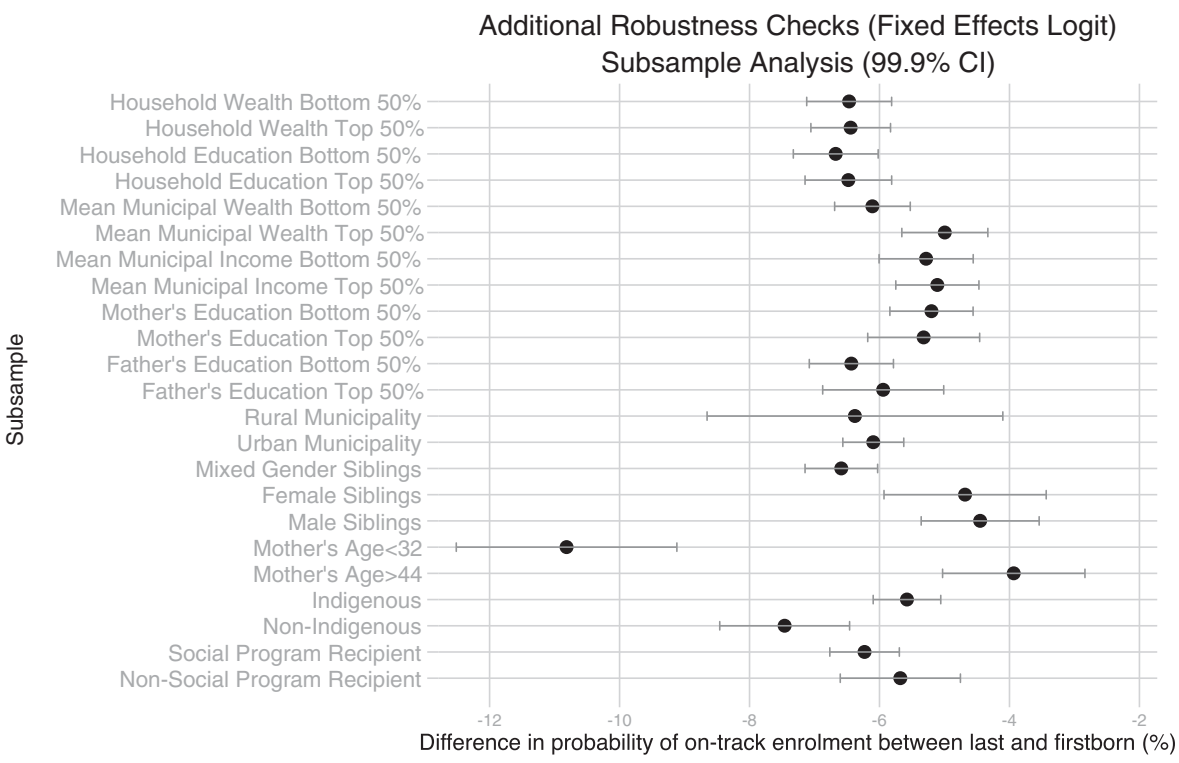

Fig. 2 Relationship between birth order and on-track enrollment across a range of subsamples defined by demographic and socioeconomic characteristics. Notes: This figure plots the difference between on-track enrollment probabilities for the last and firstborn together with the $99.9 \%$ confidence interval based on fixedeffects logit model (model 4 in Table 3) estimated in each of the subsamples indicated on the $y$-axis. These regressions are shown in Appendix 1, Tables 7 and 8

socioeconomic disparity existing in Mexico, with a substantial portion of the population living in absolute poverty at the bottom while others being considerably well-off at the top, allows for different dynamics to be in place.

In Table 5, we present fixed-effects logit models including interaction terms between birth order and our absolute and relative economic status indicators - for the full sample, single and multiple families subsamples, and subsamples defined by sibship size. Interaction terms are highly significant (in all cases, $p<0.001$ ) and consistently indicate through models $1-6$ that birth order effects are more strongly negative at higher levels of absolute wealth and less strongly negative at higher levels of relative deprivation. ${ }^{11}$ The signs of these interaction terms suggest a common direction of influence of absolute and relative economic status: the detrimental role of birth order for later-borns is more pronounced for wealthier as well as less relatively deprived households. This result is in line with the economic gradient of birth order effects observed in the literature, whereby the advantage of earlier-borns is less evident or even reversed at the bottom of the economic spectrum (e.g. de Haan et al. 2014). At the same time, our work adds the evidence that this economic gradient may stem partly from a material pathway related to economic hardship (e.g., child labor mechanisms) and partly from a psychosocial pathway based on the relative standing on the economic ladder - i.e., indicating that the macro-hierarchy the household finds itself in may affect micro-hierarchies within the household.

\footnotetext{
${ }^{11}$ The table displays only the interaction terms for absolute and relative wealth and not the covariate levels themselves because as explained above these are washed out by the fixed-effects strategy.
} 


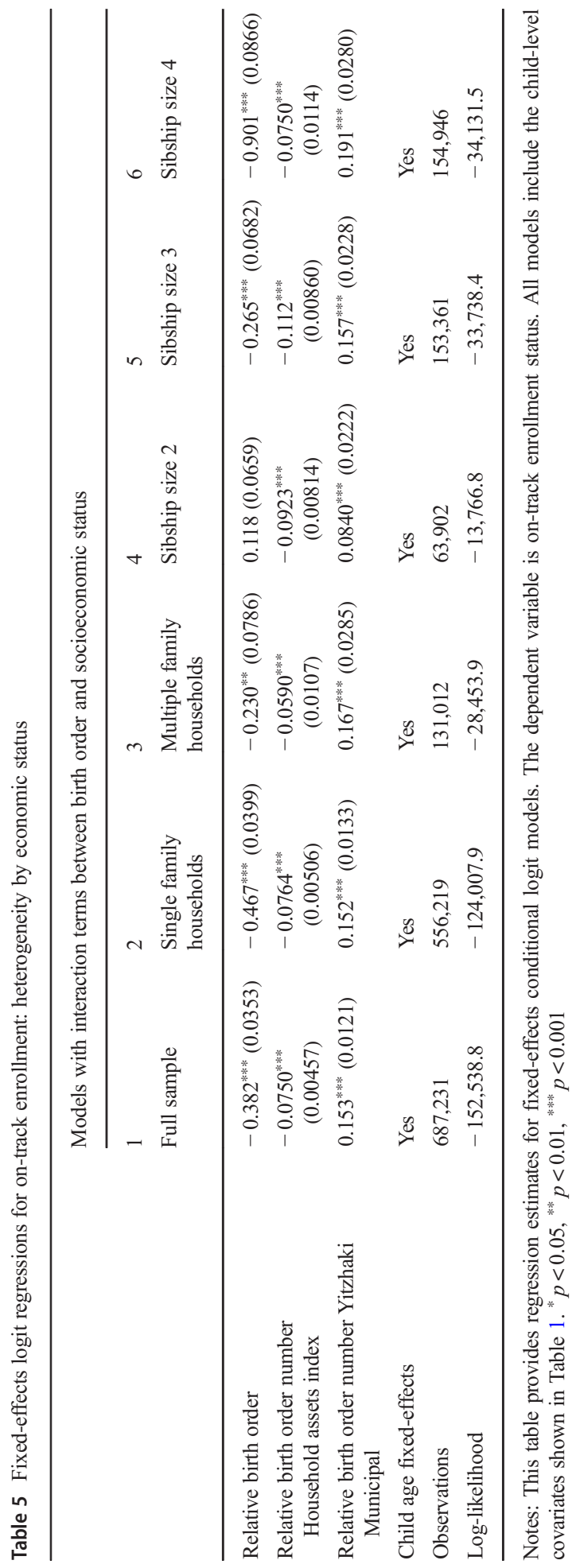


Figure 3 presents the gap in on-track enrollment between last and firstborns at different levels of absolute wealth (left) and relative deprivation (right) in terms of predicted probabilities calculated from model 1. The gaps are as expected negative, and they are consistent with the signs of the interaction terms: the educational achievement gaps in favor of earlier-borns increase at higher levels of absolute wealth and decrease at higher levels of relative deprivation. The gap in on-track grade enrollment narrows from 8.5 to $3.5 \%$ between the highest and lowest levels of absolute wealth while the corresponding changes by levels of relative deprivation are 1.5 to $6.5 \%$.

\subsection{Gender and further robustness checks}

In light of the evidence of possible gender differences in birth order effects discussed in the "Literature review" section, including a preference for firstborn males, we explore the existence of systematic gender patterns. A first insight can be gained from Fig. 2 showing that birth order effects are significant and negative, as well as of similar magnitude, across the subsamples of all female, all male, and all mixed gender siblings. To test for systematic heterogeneities in the role of birth order across gender, we first run a series of regressions where birth order variables (whether entered as dummies or in the relative operationalization) are interacted with the gender dummy. In all cases, the interaction terms are statistically insignificant, suggesting that, overall, average birth order effects tend to be similar for girls and boys. We next carry out a more fine-grained analysis with a specific focus on the gender of the first born. In particular, we divided households into six subsamples according to the gender of the firstborn (male or female) and the gender profile of the second and later-borns (all male, all female, or mixed) and estimated our baseline fixed-effects model (model 4 in Table 3 ) in each of these subsamples. ${ }^{12}$

The results are presented in Table 6, which shows that significant negative birth order effects are observed in all cases except the subsample where the firstborn is female and the other siblings are males. Predicted probabilities plotted in Fig. 4 also show that the drop in on-track enrollment is strongest when the firstborn is male, across all three gender profiles of the remaining siblings but particularly so when the other siblings are female. This suggests that parents might invest more in the firstborn when this child is a son. Taken together, these results indicate that while, overall, average birth order effects are negative and of similar magnitude for girls and boys, there is some evidence of an advantage for firstborn sons in line with the literature on Mexican firstborn cultural preferences (Rojas and Figueroa 2005; Gutmann 2006; Filmer et al. 2008).

Finally, we provide some additional robustness checks in appendices B and C. First, as we anticipated above, we run robustness checks regarding the definition of birth order-results are shown in Appendix 2, where we explore two alternative ways of ranking births. The first ranks the sons and daughters of the identified household head according to their ages. Unlike our main definition, this version focuses on the children of the household head and ignores other children living in the household who are not the head's offspring. The second alternative also ranks sons and daughters of the household head, but now includes her or his grandchildren as part of the same ranking,

$\overline{12}$ The strategy of dividing households into these subsamples is similar to that of de Haan et al. (2014) 


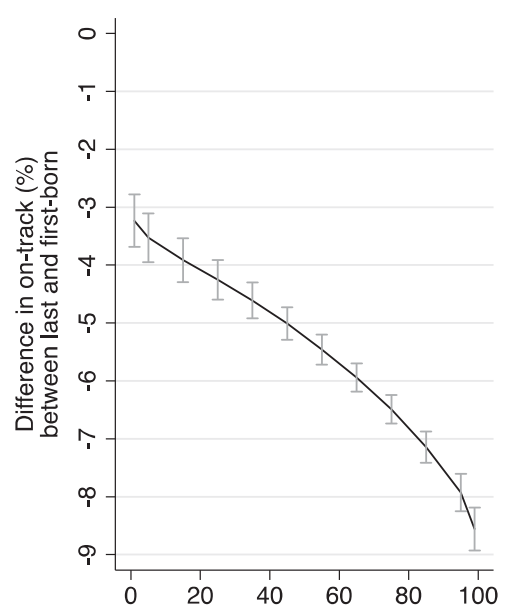

Percentiles of household absolute wealth

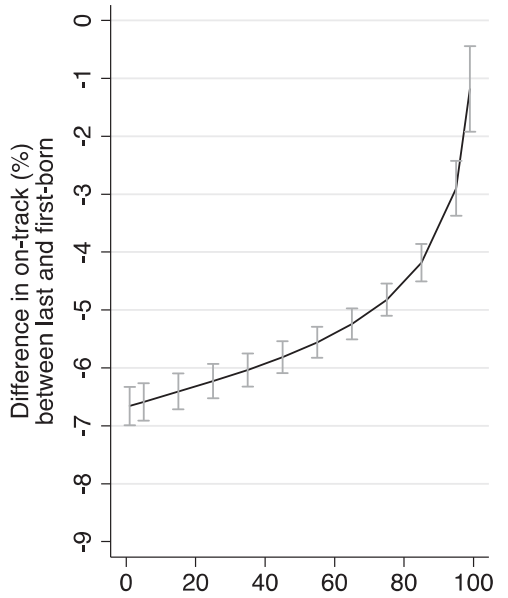

Percentiles of relative deprivation (Yitzhaki index)

Fig. 3 Birth order effects across the absolute wealth and relative deprivation domains. Notes: This figure shows the gap in on-track $(\%)$ between lastborn and firstborns in terms of predicted probabilities obtained using model 1 in Table 5 at respective percentiles household absolute wealth (left) and relative deprivation (right) together with $95 \%$ confidence intervals (all other covariates are held fixed at their sample values)

assuming that families in these settings still bow to the grandparents' decisions. Birth order are consistently negative and statistically significant $(p<0.001)$ under these alternative definitions.

Second, since one of the novelties of our paper is the incorporation of relative standard of living as a dimension of economic status in the study of birth order effects, we investigate the interaction between birth order and alternative metrics of relative deprivation. As we mentioned above, we use indices which differ in the functional form used (i.e., the concave index proposed by Esposito 2010), the (own-generated) mean municipal wealth as well as the official mean income in the municipality taken from the National Statistical Office (INEGI, Consejo Nacional de Población CONAPO). These results, provided in Appendix 3, indicate that the pattern of interaction effects remains consistent across all three alternatives - that is, birth order effects are strengthened at higher levels of not only absolute wealth but also of relative wealth (i.e., lower levels of relative deprivation) also in the case of these alternative formulations of relative deprivation.

\section{Conclusion}

We have examined birth order effects on on-track age-for-grade school enrollment using over 2 million observations from the 2010 extended questionnaire of the Mexican census. We have found that birth order effects are consistently negative through a number of robustness checks and that this result likely warrants a causal interpretation, as it holds across models designed to address specific endogeneity concern. Beyond customary logit models, we have estimated fixed-effects models focusing on withinhousehold outcome variation, models based on a variety of subsamples defined by 


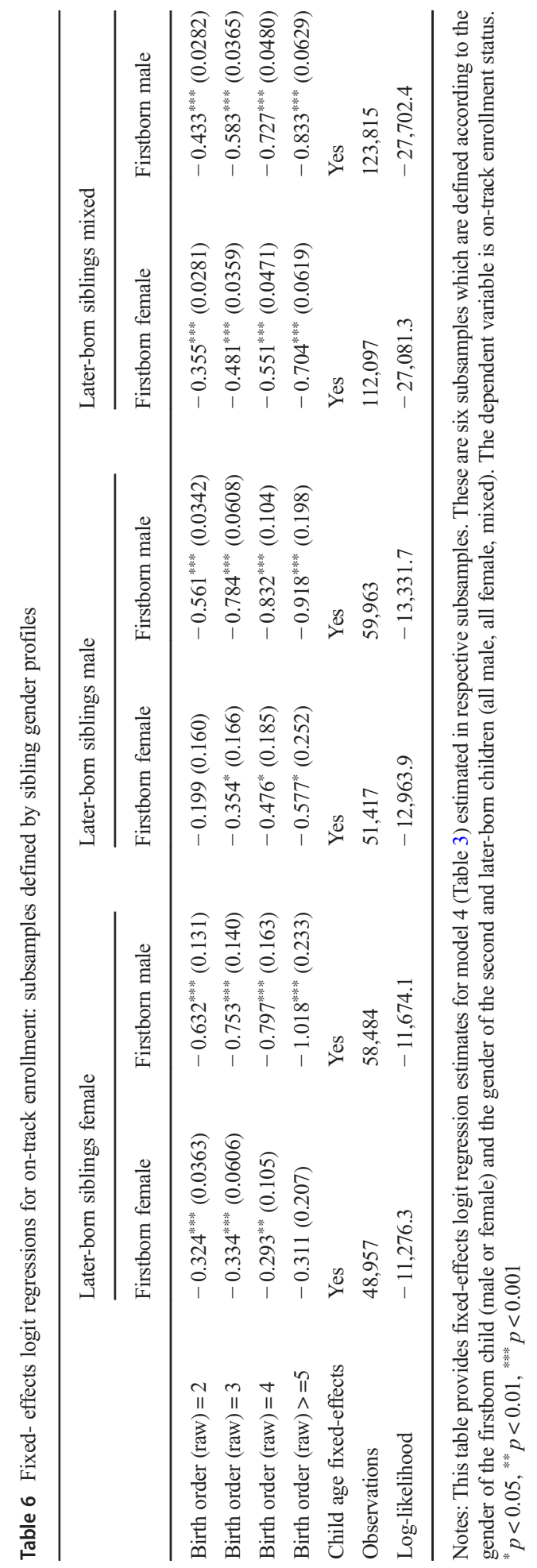



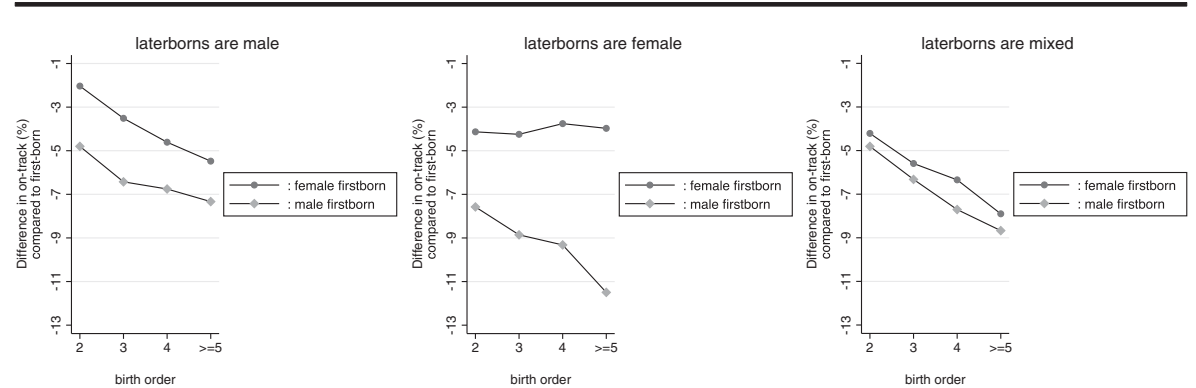

Fig. 4 Birth order effects and sibling gender profiles. Notes: This figure shows predicted probabilities obtained using the six subsample-wise fixed-effects logit regressions shown in Table 5 by varying birth order while holding all other covariates fixed at their sample values. The numbers shown are the difference in probability of being on-track between respective birth order levels $(2,3,4,5$, and above) and that of the firstborn

socioeconomic and demographic lines including the number of siblings and maternal age, models employing a relative birth order metric as well as models using birth order dummies, and models adopting alternative approaches for attributing birth ranks. Thinking of Mexico as an upper middle-income country and an OECD member, our evidence tallies with the literature wherein economically developed countries tend to have negative birth order effects - while the opposite is generally found for developing countries. It should also be considered that the prevalence of child labor has been lessened by the major conditional cash transfer program Progresa/Oportunidades introduced in 1997 (Behrman et al. 2011) — hence, possibly decreasing the strength of this factor driving positive birth order effects. At the same time, however, striking socioeconomic inequalities, the high incidence of poverty, and the fact that child labor still exists (Alcaraz et al. 2012), all suggest that there might exist certain mechanisms which shape birth order effects in ways that are similar to developing countries.

We investigate the heterogeneity of birth order effects at different levels of economic status, which, for the first time in the study of birth orders, we conceptualize in terms of not only absolute wealth but also relative deprivation. We estimate additional models featuring interaction terms between birth order and our two dimensions of economic status, with the aim of shedding light on the economic gradient of birth order effects and saying something more about potential mechanisms at play. These models provide consistent results across the full sample as well as subsamples by sibship size, suggesting that fertility decisions are likely to be exogenous to these interaction effects. We find that, ceteris paribus, higher absolute wealth is associated with stronger, more negative birth order effects. The pattern is suggested by the sign of the interaction term and is borne out by graphical analysis, and is consistent with evolutionary models of biased parental investment (which predict that earlier-borns' advantage would be magnified in richer households), as well as the existence of child labor (which is more detrimental for earlier-borns and is arguably more prevalent amongst poor households).

Reinforcing this effect, higher relative standards of living (i.e., lower relative deprivation) is also associated with more negative birth order effects. We have suggested alternative views on the possible role of relative deprivation, but a clear-cut interpretation of our finding in this case is more complicated given the lack of literature on the heterogeneity of birth order effects at different levels of relative standards of living (absolute standards of living being controlled for). The negative role of relative 
deprivation in models where absolute wealth is controlled for suggests that the economic gradient in education results not only from a material pathway, related to credit constraints, affordability of education and physical inputs (Basu and Van 1998), but also from a psychosocial pathway whereby relative standing in society affects human capital investments through curbing aspirations and shaping social identities (Mayer 2001; Destin and Oyserman 2009 and 2010). The positive sign of the interaction term between birth order and relative deprivation in our regressions suggests therefore that birth order differences in educational outcomes may stem from the place occupied by the household in the economic hierarchy and from the way socioeconomic status affects how parents and children see their present and future roles in society.

Taken together, our findings suggest key policy implications. In common with studies from other contexts, our results highlight the importance of focusing on laterborn children in the Mexican context in order to improve educational outcomes, given that birth order effects can explain around $6 \%$ of the variation in on-track grade enrollment. Second, our results emphasize the importance of recognizing socioeconomic status as a multidimensional phenomenon, characterized by both absolute and relative domains. These are likely to exert independent as well as joint influence over educational outcomes in Mexico, suggesting that the striking socioeconomic disparities in the country may have more complex and detrimental repercussions on human capital accumulation than previously thought. In addition, while we find, overall, similar birth order effects for girls and boys, we have found evidence of an advantage for firstborn sons. This is in line with the literature on firstborn- as well as son-preferences in the country, which are aspects of a patriarchal culture Mexican policymakers should address.

Finally, while the size and richness of our data allow us to conduct our analysis with significant precision and implement several robustness checks, important limitations should be acknowledged. The first and perhaps most obvious one resides in the crosssectional nature of our data, which deprives our analysis of a potentially useful longitudinal component. This would have been useful in ascertaining the exact mechanisms at play behind absolute and relative wealth. We have employed fixed-effects models to strengthen the claim around causality of the observed negative birth order effects, but these models are limited in their ability to delve into the role of householdlevel characteristics because by construction they are washed out. Therefore, there remains the possibility that some components of socioeconomic status might be endogenous to birth order. For instance, a common set of unobservables might determine relative deprivation through households' choice of where to live, as well as birth order via fertility decisions. In addition, while our focus is on birth order mechanisms related to economic status, it is likely that other mechanisms related to physiological, cultural, and intra-household factors also operate simultaneously-and possibly in interplay with socioeconomic domains. A key avenue for future research is to understand how socioeconomic domains interconnect with other factors to co-determine birth order effects.

\section{Compliance with ethical standards}

Conflict of interest The authors declare that they have no conflict of interest. 
กิำ

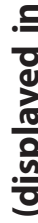

密

产

름

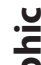

跣

要

ลิ

造

ᄒ

$\frac{n}{a}$

$\frac{1}{8}$

$\stackrel{5}{*}$

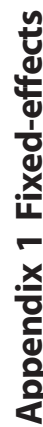




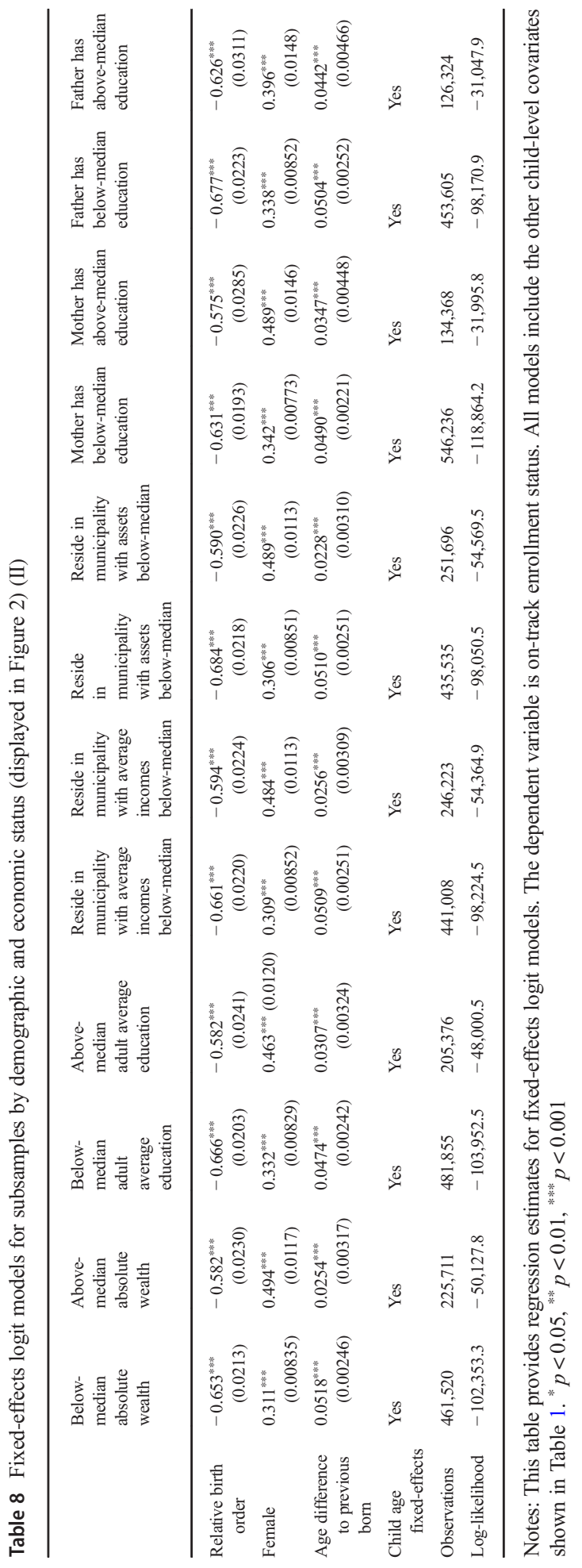


Appendix 2 Fixed-effects logit models for alternative ways of ranking birth order

Table 9 Fixed-effects logit models for alternative ways of ranking birth order

\begin{tabular}{|c|c|c|c|c|}
\hline & \multicolumn{2}{|l|}{ First alternative } & \multicolumn{2}{|l|}{ Second alternative } \\
\hline & $\begin{array}{l}\text { Relative } \\
\text { birth order }\end{array}$ & $\begin{array}{l}\text { Birth order } \\
\text { dummies }\end{array}$ & $\begin{array}{l}\text { Relative } \\
\text { birth order }\end{array}$ & $\begin{array}{l}\text { Birth } \\
\text { order dummies }\end{array}$ \\
\hline Relative birth order & $-0.733^{* * * *}(0.0175)$ & & $-0.738^{* * *}(0.0172)$ & \\
\hline Birth order $($ raw $)=2$ & & $-0.305^{* * * *}(0.0101)$ & & $-0.326^{* * * *}(0.0103)$ \\
\hline Birth order $($ raw $)=3$ & & $-0.357^{* * * * *}(0.0147)$ & & $-0.428^{* * * *}(0.0151)$ \\
\hline Birth order $($ raw $)=4$ & & $-0.368^{* * * *}(0.0205)$ & & $-0.491^{* * *}(0.0209)$ \\
\hline Birth order (raw) $>=5$ & & $-0.359^{* * * *}(0.0268)$ & & $-0.555^{* * *}(0.0274)$ \\
\hline Female & $0.369^{* * * * *}(0.00709)$ & $0.358^{* * * * *}(0.00659)$ & $0.372^{* * * *}(0.00686)$ & $0.357^{* * * * *}(0.00658)$ \\
\hline $\begin{array}{l}\text { Age difference to } \\
\text { previous born }\end{array}$ & $0.0355^{\text {**** }}(0.00209)$ & $0.0408^{\text {**** }}(0.00223)$ & $0.0328^{\text {**** }}(0.00195)$ & $0.0355^{\text {*决 }}(0.00216)$ \\
\hline Child age fixed-effects & Yes & Yes & Yes & Yes \\
\hline Observations & 630,572 & 709,171 & 673,657 & 711,087 \\
\hline Log-likelihood & $-140,076.2$ & $-163,255.2$ & $-149,658.5$ & $-163,541.2$ \\
\hline
\end{tabular}

Notes: This table provides regression estimates for fixed-effects logit models. The dependent variable is ontrack enrollment status. The two alternative ways of ranking birth order are as follows. The first ranks the sons and daughters of the identified household head according to their ages and ignores other children living in the household who are not the head's offspring. The second alternative also ranks sons and daughters of the household head but also includes her or his grandchildren as part of the same ranking. All models include the other child-level covariates shown in Table $1 .{ }^{*} p<0.05,{ }^{* *} p<0.01,{ }^{* * * *} p<0.001$ 


\section{Appendix 3 Fixed-effects logit models for the interaction between economic status and birth order using alternative metrics of relative deprivation}

Table 10 Fixed-effects logit models for the interaction between economic status and birth order using alternative metrics of relative deprivation

\begin{tabular}{|c|c|c|c|}
\hline & \multicolumn{3}{|c|}{ Metric of relative deprivation } \\
\hline & Esposito (2010) & $\begin{array}{l}\text { Municipality-average } \\
\text { level of assets }\end{array}$ & $\begin{array}{l}\text { Municipality-average } \\
\text { level of income }\end{array}$ \\
\hline Relative birth order & $-0.531^{* * * *}(0.0424)$ & $-0.397^{* * * *}(0.0326)$ & $-0.105^{* * *}(0.0277)$ \\
\hline $\begin{array}{l}\text { Relative birth order number } \\
\text { Household assets index }\end{array}$ & $-0.0547^{* * *}(0.00535)$ & $-0.185^{\text {**** }}(0.00643)$ & $-0.114^{* * *}(0.00543)$ \\
\hline $\begin{array}{l}\text { Relative birth order number } \\
\text { Relative deprivation } \\
\text { Esposito metric }\end{array}$ & $0.803^{* * *}(0.0601)$ & & \\
\hline $\begin{array}{l}\text { Relative birth order number } \\
\text { Mean municipal asset index }\end{array}$ & & $0.134^{* * *}(0.00780)$ & \\
\hline $\begin{array}{l}\text { Relative birth order number } \\
\text { Mean income per } \\
\text { municipality } 2010\end{array}$ & & & $0.0000418^{* * *}(0.0000110)$ \\
\hline Female & $0.372^{* * *}(0.00680)$ & $0.372^{* * *}(0.00681)$ & $0.373^{* * *}(0.00680)$ \\
\hline Age difference to previous born & $0.0410^{* * * *}(0.00195)$ & $0.0408^{* * * *}(0.00195)$ & $0.0416^{* * * *}(0.00194)$ \\
\hline Child age fixed-effects & Yes & Yes & Yes \\
\hline Observations & 687,231 & 687,231 & 687,231 \\
\hline Log-likelihood & $-152,531.0$ & $-152,473.1$ & $-152,613.5$ \\
\hline
\end{tabular}

Notes: This table provides regression estimates for fixed-effects logit models. The dependent variable is ontrack enrollment status. All models include the other child-level covariates shown in Table $1 .{ }^{*} p<0.05$, ${ }^{* *} p<0.01,{ }^{* * *} p<0.001$

Open Access This article is licensed under a Creative Commons Attribution 4.0 International License, which permits use, sharing, adaptation, distribution and reproduction in any medium or format, as long as you give appropriate credit to the original author(s) and the source, provide a link to the Creative Commons licence, and indicate if changes were made. The images or other third party material in this article are included in the article's Creative Commons licence, unless indicated otherwise in a credit line to the material. If material is not included in the article's Creative Commons licence and your intended use is not permitted by statutory regulation or exceeds the permitted use, you will need to obtain permission directly from the copyright holder. To view a copy of this licence, visit http://creativecommons.org/licenses/by/4.0/.

\section{References}

Adli R, Louichi A, Tamouh N (2010) The sibling size impact on the educational achievement in France. Educ Econ 18(3):331-348

Alcaraz C, Chiquiar D, Salcedo A (2012) Remittances, schooling, and child labor in Mexico. J Dev Econ 97(1):156-165

Baer M, Oldham GR, Hollingshead AB, Costa Jacobsohn G (2005) Revisiting the birth order-creativity connection: the role of sibling constellation. Creat Res J 17(1):67-77 
Balsa AI, French MT, Regan TL (2014) Relative deprivation and risky behaviors. J Hum Resour 49(2):446-471

Barclay KJ (2015) Birth order and educational attainment: evidence from fully adopted sibling groups. Intelligence 48:109-122

Barclay K, Myrskylä M, Tynelius P, Berglind D, Rasmussen F (2016) Birth order and hospitalization for alcohol and narcotics use in Sweden. Drug Alcohol Depend 167:15-22

Basu K, Van PH (1998) The economics of child labor. Am Econ Rev:412-427

Becker GS, Tomes N (1976) Child endowments and the quantity and quality of children. J Polit Econ 84: S143-S162

Behrman JR, Taubman P (1986) Birth order, schooling, and earnings. J Labor Econ 4(3):S121-S145

Behrman JR, Parker SW, Todd PE (2011) Do conditional cash transfers for schooling generate lasting benefits? A five-year followup of PROGRESA/Oportunidades. J Hum Resour 46(1):93-122

Belmont L, \& Marolla FA (1973) Birth order, family size, and intelligence: A study of a total population of 19year-old men born in the Netherlands is presented. Science, 182(4117): 1096-1101

Bertoni M, Brunello G (2016) Later-borns don't give up: the temporary effects of birth order on European earnings. Demography 53(2):449-470

Binder M (1998) Family background, gender and schooling in Mexico. J Dev Stud 35(2):54-71

Binder M, Woodruff C (2002) Inequality and intergenerational mobility in schooling: the case of Mexico. Econ Dev Cult Chang 50(2):249-267

Black SE, Devereux PJ, Salvanes KG (2005) The more the merrier? The effect of family size and birth order on children's education. The Quarterly Journal of Economics:669-700

Black SE, Devereux PJ, Salvanes KG (2016) Healthy (?), wealthy, and wise: birth order and adult health. Econ Hum Biol 23:27-45

Black SE, Grönqvist E, Öckert B (2017) Born to lead? The effect of birth order on non-cognitive abilities. IZA Discussion Paper No 10560

Blake J (1981) Family size and the quality of children. Demography 18:421-442

Booth AL, Kee HJ (2009) Birth order matters: the effect of family size and birth order on educational attainment. J Popul Econ 22(2):367-397

Byrd RS, Weitzman M, Auinger P (1997) Increased behavior problems associated with delayed school entry and delayed school progress. Pediatrics 100(4):654-661

Cho H (2011) Birth order and education: evidence from a Korean cohort. Econ Lett 110(3):200-202

Clark AE, D'Ambrosio C (2015) Attitudes to income inequality: experimental and survey evidence. In: Handbook of income distribution, vol 2. Elsevier, pp 1147-1208

Clark AE, Frijters P, Shields MA (2008) Relative income, happiness, and utility: an explanation for the Easterlin paradox and other puzzles. J Econ Lit 46(1):95-144

Clutton-Brock TH (1991) The evolution of parental care. Princeton University Press

CONEVAL (2012) Report of poverty in Mexico 2010: the country, its states and its municipalities. National Council for the Evaluation of Social Development Policy Mexico, Federal District

Conley D, Glauber R (2006) Parental educational investment and children's academic risk. Estimates of the impact of sibship size and birth order from exogenous variation in fertility. J Hum Resour 41(4):722-737

Dammert AC (2010) Siblings, child labor, and schooling in Nicaragua and Guatemala. J Popul Econ 23(1):199-224

Dayioğlu M, Kirdar MG, Tansel A (2009) Impact of sibship size, birth order and sex composition on school enrolment in urban Turkey. Oxf Bull Econ Stat 71(3):399-426

de Haan M (2010) Birth order, family size and educational attainment. Econ Educ Rev 29(4):576-588

de Haan M, Plug E, Rosero J (2014) Birth order and human capital development evidence from Ecuador. J Hum Resour 49(2):359-392

Deaton A (2001) Relative deprivation, inequality, and mortality (No. w8099). National Bureau of economic research

Debowicz D, Golan J (2014) The impact of Oportunidades on human capital and income distribution in Mexico: a top-down/bottom-up approach. J Policy Model 36(1):24 42

Destin M, Oyserman D (2009) From assets to school outcomes: how finances shape children's perceived possibilities and intentions. Psychol Sci 20(4):414-418

Destin M, Oyserman D (2010) Incentivizing education: seeing schoolwork as an investment, not a chore. J Exp Soc Psychol 46(5):846-849

Doi, Suhail AR, Williams GM (2013) Methods of Clinical Epidemiology. Springer Science \& Business Media, Berlin

Ejrnæs M, Pörtner CC (2004) Birth order and the intrahousehold allocation of time and education. Rev Econ Stat 86(4):1008-1019

Emerson PM, Souza AP (2008) Birth order, child labor, and school attendance in Brazil. World Dev 36(9): 1647-1664

Esposito L (2010) Upper boundedness for the measurement of relative deprivation. Rev Income Wealth 56(3): 632-639 
Esposito L, Villaseñor A (2019) Relative deprivation and school enrolment. Evidence from Mexico. Review of Income and Wealth 65(1):166-186

Ferrer-i-Carbonell A (2005) Income and well-being: an empirical analysis of the comparison income effect. J Public Econ 89(5):997-1019

Filmer D, Pritchett LH (2001) Estimating wealth effects without expenditure data — or tears: an application to educational enrollments in states of India. Demography 38(1):115-132

Filmer D, Friedman J, Schady N (2008) Development, modernization, and son preference in fertility decisions. The World Bank

Galton F (1874) English men of science: their nature and nurture. MacMillan, London

García-Pérez JI, Hidalgo-Hidalgo M, Robles-Zurita JA (2014) Does grade retention affect students' achievement? Some evidence from Spain. Appl Econ 46(12):1373-1392

Gibbs BG, Heaton TB (2014) Drop out from primary to secondary school in Mexico: a life course perspective. Int J Educ Dev 36:63-71

Gibson MA, Lawson DW (2011) "Modernization” increases parental investment and sibling resource competition: evidence from a rural development initiative in Ethiopia. Evol Hum Behav 32(2):97-105

Gibson MA, Sear R (2010) Does wealth increase parental investment biases in child education? Evidence from two African populations on the cusp of the fertility transition. Curr Anthropol 51(5):693-701

Glick P, Sahn DE (2010) Early academic performance, grade repetition, and school attainment in Senegal: a panel data analysis. World Bank Econ Rev 24(1):93-120

Gutmann MC (2006) The Meanings of Macho: being a man in Mexico City, vol 3. University of California Press

Hanushek EA (1992) The trade-off between child quantity and quality. J Polit Econ:84-117

Härkönen J (2014) Birth order effects on educational attainment and educational transitions in West Germany. Eur Sociol Rev 30(2):166-179

Hausman JA, Abrevaya J, Scott-Morton FM (1998) Misclassification of the dependent variable in a discreteresponse setting. J Econ 87:239-269

Hedges S, Mulder MB, James S, Lawson DW (2016) Sending children to school: rural livelihoods and parental investment in education in northern Tanzania. Evol Hum Behav 37(2):142-151

Herd P, Higgins J, Sicinski K, Merkurieva I (2016) The implications of unintended pregnancies for mental health in later life. Am J Public Health 106(3):421-429

Horrace WC, Oaxaca RL (2006) Results on the bias and inconsistency of ordinary least squares for the linear probability model. Econ Lett 90:321-327

Hotz VJ, \& Pantano J (2015) Strategic parenting, birth order, and school performance. Journal of population economics, 28(4): 911-936

Jaekel J, Strauss VYC, Johnson S, Gilmore C, Wolke D (2015) Delayed school entry and academic performance: a natural experiment. Dev Med Child Neurol 57(7):652-659

Jayachandran S, Pande R (2017) Why are Indian children so short? The role of birth order and son preference. Am Econ Rev 107(9):2600-2629

Jeon J (2008) Evolution of parental favoritism among different-aged offspring. Behav Ecol 19(2):344-352

Jimerson SR (1999) On the failure of failure: examining the association between early grade retention and education and employment outcomes during late adolescence. J Sch Psychol 37(3):243-272

Kantarevic J, Mechoulan S (2006) Birth order, educational attainment, and earnings: an investigation using the PSID. J Hum Resour 41(4):755-777

Kessler D (1991) Birth order, family size, and achievement: family structure and wage determination. J Labor Econ 9:413-426

Kolenikov S, Angeles G (2009) Socioeconomic status measurement with discrete proxy variables: is principal component analysis a reliable answer? Rev Income Wealth 55(1):128-165

Kudrna L, Furnham A, Swami V (2010) The influence of social class salience on self-assessed intelligence. Soc Behav Personal Int J 38(6):859-864

Lafortune J, Lee S (2014) All for one? Family size and children's educational distribution under credit constraints. Am Econ Rev 104(5):365-369

Lawson DW, Mace R (2009) Trade-offs in modern parenting: a longitudinal study of sibling competition for parental care. Evol Hum Behav 30(3):170-183

Liddell C, Barrett L, Henzi P (2003) Parental investment in schooling: evidence from a subsistence farming community in South Africa. Int J Psychol 38(1):54-63

Long JS (1997) Regression models for categorical and limited dependent variables, 1st edn. Sage Publications, Inc Luttmer EF (2005) Neighbors as negatives: relative earnings and well-being. Q J Econ 120(3):963-1002

Malaspina D, Reichenberg A, Weiser M, Fennig S, Davidson M, Harlap S et al (2005) Paternal age and intelligence: implications for age-related genomic changes in male germ cells. Psychiatr Genet 15(2):117-125

Manacorda M (2012) The cost of grade retention. Rev Econ Stat 94(2):596-606 
Massey DS, Espinosa KE (1997) What's driving Mexico-US migration? A theoretical, empirical, and policy analysis. Am J Sociol 102(4):939-999

Mayer SE (2001) How did the increase in economic inequality between 1970 and 1990 affect children's educational attainment? Am J Sociol 107(1):1-32

Mazzonna F (2014) The long-lasting effects of family background: a European cross-country comparison. Econ Educ Rev 40:25-42

McKenzie DJ (2005) Measuring inequality with asset indicators. J Popul Econ 18(2):229-260

Mechoulan S, Wolff FC (2015) Intra-household allocation of family resources and birth order: evidence from France using siblings data. J Popul Econ 28(4):937-964

Mishra S, Novakowski D (2016) Personal relative deprivation and risk: an examination of individual differences in personality, attitudes, and behavioral outcomes. Personal Individ Differ 90:22-26

Modin B (2002) Birth order and educational career: a study of school performance and achieved education of children born in early-twentieth-century Sweden. J Fam Hist 27(1):25-39

Monfardini C, See SG (2016) Birth order and child cognitive outcomes: an exploration of the parental time mechanism. Educ Econ:1-15

Napoletano A, Elgar FJ, Saul G, Dirks M, Craig W (2016) The view from the bottom: relative deprivation and bullying victimization in Canadian adolescents. Journal of interpersonal violence 31(20):3443-3463

Odgers CL, Donley S, Caspi A, Bates CJ, Moffitt TE (2015) Living alongside more affluent neighbors predicts greater involvement in antisocial behavior among low-income boys. J Child Psychol Psychiatry 56(10):1055-1064

OECD (2016) OECD regions at a glance 2016. OECD Publishing

Organisation for Economic Co-operation and Development (2011) When students repeat grades or are transferred out of school: what does it mean for education systems? OECD Publishing

Parish WL, Willis RJ (1993) Daughters, education, and family budgets: Taiwan experiences. J Hum Resour 28(4):863-898

Patrinos HA, Psacharopoulos G (1997) Family size, schooling and child labor in Peru-an empirical analysis. J Popul Econ 10(4):387-405

Pavan R (2015) On the production of skills and the birth order effect. J Hum Resour 51(3):699-726

Price J (2008) Parent-child quality time does birth order matter? J Hum Resour 43(1):240-265

Quinlan RJ (2007) Human parental effort and environmental risk. Proceedings of the Royal Society B: Biological Sciences 247:121-125

Rammohan A, Dancer D (2008) Gender differences in intrahousehold schooling outcomes: the role of sibling characteristics and birth-order effects. Educ Econ 16(2):111-126

Rodgers JL (2014) Are birth order effects on intelligence really Flynn effects? Reinterpreting Belmont and Marolla 40 years later. Intelligence 42:128-133

Rojas O, Figueroa JG (2005) "El comportamiento reproductivo de los varones: el caso de los derechohabientes del Instituto Mexicano del Seguro Social”, in D. Castillo (ed.), Dinámica demográfica y cambio social en América Latina, Universidad Autónoma del Estado de México y Asociación Latinoamericana de Sociología, Toluca, Mexico

Saad G, Gill T, Nataraajan R (2005) Are laterborns more innovative and nonconforming consumers than firstborns? A Darwinian perspective. J Bus Res 58(7):902-909

Salmon C, Cuthbertson AM, Figueredo AJ (2016) The relationship between birth order and prosociality: an evolutionary perspective. Personal Individ Differ 96:18-22

Seid Y, Gurmu S (2015) The role of birth order in child labor and schooling. Appl Econ 47(49):5262-5281

Sulloway FJ (1996) Born to rebel: birth order family dynamics, and creative lives. Pantheon, New York

Tenikue M, Verheyden B (2010) Birth order and schooling: theory and evidence from twelve sub-saharan countries. J Afr Econ 19(4):459-495

UNESCO (2007) Urban and Rural Disparities in Latin America: Their Implications for Education Access. Buenos Aires

Vogel M, South SJ (2016) Spatial dimensions of the effect of neighborhood disadvantage on delinquency. Criminology 54(3):434-458

World Bank, World Development Report (2012) Gender Equality and Development, Washington, DC

Yitzhaki S (1979) Relative deprivation and the Gini coefficient. Q J Econ:321-324

Zajonc RB, Markus GB (1975) Birth order and intellectual development. Psychol Rev 82:74-88

Publisher's note Springer Nature remains neutral with regard to jurisdictional claims in published maps and institutional affiliations. 